\title{
MICROENCAPSULAÇÃO DE POLPA DE GOIABA: AVALIAÇÃO DA MORFOLOGIA
}

\author{
O. M. PORCU ${ }^{1}$, D. XAVIER ${ }^{2}$
}

${ }^{1}$ Universidade Tecnológica Federal do Paraná - Campus Medianeira, SEBLIC - Química, Docente, Programa Pós Graduação em Processos Químicos e Bioquímicos - Campus Pato Branco

${ }^{2}$ Universidade Tecnológica Federal do Paraná, Departamento de Engenharia Ambiental E-mail para contato: ornellamporcu@gmail.com

RESUMO - A técnica de microencapsulação envolve a ação de um material de parede que pode oferecer solubilidade e incorporação melhorada, maior estabilidade à oxidação e maior período de armazenamento. Este estudo objetivou a avaliação da morfologia externa das microcápsulas de polpa de goiaba (MG) por Microscopia Eletrônica de Varredura (Mev). Polpa de goiaba (cultivar Paluma) microencapsulada com dextrina (1:1) foi obtida por atomização (spray dryer). As amostras de MG foram submetidas a fotomicrografias eletrônicas em microscópio eletrônico de varredura de bancada utilizando uma aceleração de voltagem de $5 \mathrm{kV}$. As amostras foram observadas sob ampliações de 2000x; 1500x; e, 1000x. As micropartículas formadas apresentaram um grau de aglomeração com variação no tamanho (de 2,68 a 6,79 $\mu \mathrm{m}$ ) mas com formato esférico. A obtenção destas características indicou sucesso no processo de microencapsulação

\section{INTRODUÇÃO}

A goiaba (Psidium guajava L) é um fruto muito cultivado no Brasil, que está entre os principais produtores, tendo um volume de produção anual de 300 mil toneladas (Brackmann et al., 2012). A goiaba é utilizada como fruta fresca para o consumo humano, além de inúmeras outras formas, como: purê ou polpa de goiaba, néctar, suco, compota, goiabada, doces, geleias e sorvete (Nascimento, 2010).

Esta fruta tem quantidade significativa de compostos antioxidantes, como vitamina C, carotenoides e compostos fenólicos. Estes compostos agem no organismo capturando os radicais livres e tendo ações anti-inflamatórias, antiplaquetárias, anticancerígenas e hipoglicemiantes (Freire et al., 2012; Haida et al., 2011).

Os antioxidantes são substâncias facilmente degradadas por fatores ambientais. Alguns processos industriais são aplicados para que se conserve a integridade destes compostos. Um deles é a microencapsulação.

A microencapsulação é um processo criado com o objetivo de evitar a oxidação e decomposição 
de substâncias sensíveis. Pode ser definida como um processo que resulta no envolvimento de pequenas partículas por uma membrana. Esta membrana protege a substância de condições adversas ao meio como, luz, umidade, oxigênio e reações com outros compostos, estabilizando o produto. Assim, aumenta-se a vida útil do produto e controla-se a liberação do encapsulado (Santos; FávaroTrindade; Grosso, 2005).

Sendo assim, o aproveitamento da goiaba é de grande importância, pois pode agregar sabor, aroma e valor nutricional à produtos alimentícios. Para isso, desenvolveram-se microcápsulas de goiaba através do microencapsulamento por atomização, utilizando como agente encapsulante a dextrina.

O objetivo deste estudo foi obter a polpa de goiaba microencapsulada e avaliar a morfologia externa do produto obtido através da microscopia eletrônica de varredura (Mev).

\section{MATERIAL E MÉTODOS}

Esta pesquisa foi desenvolvida na Universidade Tecnológica Federal do Paraná, Campus Pato Branco, no Laboratório de Qualidade Agroindustrial - LAQUA.

\subsection{Microencapsulação por Atomização (Spray drying)}

Para o processo de microencapsulação, foi utilizado purê de goiaba fornecido por uma Indústria de Alimentos do estado de Santa Catarina. A polpa de goiaba, designado por (G), foi transportado embalado em saco plástico revestido de aço. A variedade da goiaba utilizada para o purê foi a Paluma, sendo que esta é a mais utilizada industrialmente. As polpas de goiaba foram mantidos congelados a $10^{\circ} \mathrm{C}$ até a utilização.

O purê de goiaba é definido segundo a Instrução Normativa n. 01, de 7 de janeiro de 2000, onde: polpa ou purê de goiaba é o produto não fermentado e não diluído, obtido da parte comestível da goiaba (Psdium guaiajava L.), através de processo tecnológico adequado, com teor mínimo de sólidos totais (BRASIL, 2000).

A polpa de goiaba foi submetido a microencapsulação por atomização, utilizando-se dextrina, obtida do amido de mandioca, como agente encapsulante.

Utilizou-se uma proporção de 1:1 de dextrina e purê de goiaba, obtendo-se na mistura final um teor de sólidos solúveis de $15{ }^{\circ}$ Brix. O preparo da mistura a ser encapsulada consistiu em adicionar $200 \mathrm{~mL}$ de água a $49 \mathrm{~g}$ de dextrina, aquecendo-se a mistura a $80{ }^{\circ} \mathrm{C}$, agitando-se em agitador 
mecânico de bancada (Fisatam 713D AAKER) a $4800 \mathrm{rpm}$ por 3 minutos para que a dextrina se dissolvesse na água. Foi adicionado à mistura anterior, $500 \mathrm{~g}$ de purê de goiaba, voltando à agitação por mais 3 minutos.

Em seguida, a atomização foi conduzida em um spray dryer (Lab Maq MSD 1.0), dimensões 1800 × 500 × $800 \mathrm{~mm}, 160 \mathrm{Kg}$, capacidade máxima de secagem 1 litro por hora. Foi utilizado bico pneumático de 2 fluidos com $1 \mathrm{~mm}$ de abertura e fluxo de ar comprimido para secagem de 45 L.min1. A temperatura de secagem variou de 40 a $60{ }^{\circ} \mathrm{C}$ e a velocidade de secagem de $0,54 \mathrm{~L} . \mathrm{h}^{-1}$.

\subsection{Avaliação da Morfologia Externa das Microcápsulas de Goiaba por Microscopia Eletrônica de Varredura (Mev)}

As microcápsulas de goiaba foram submetidas a fotomicrografias eletrônicas em um microscópio eletrônico de varredura de bancada (Hitachi, TM 300), utilizando uma aceleração de voltagem de $5 \mathrm{kV}$. Através disso, foi possível visualizar a morfologia das amostras e obter os diâmetros das cápsulas.

\section{Resultados e Discussões}

Os aspectos microestruturais das partículas de (MG) foram analisadas por Mev e observadas sob ampliação de 1000x, 1500x, e 2000x, conforme é visto na Figura 1, 2 e 3, respectivamente.

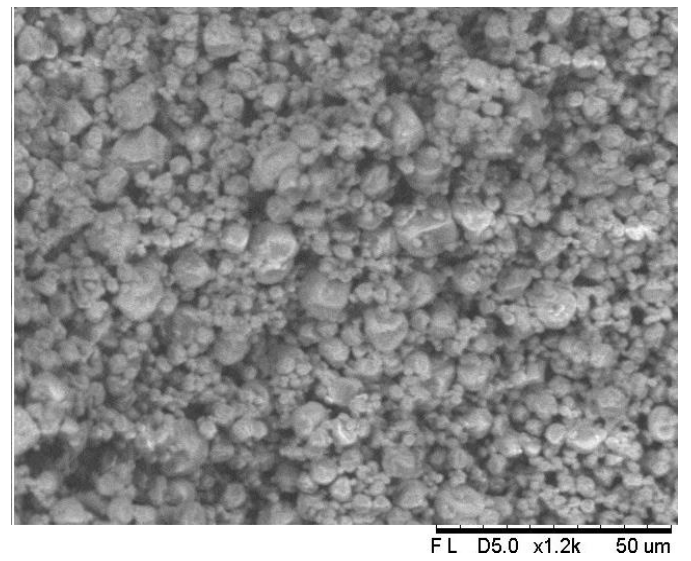

Figura 1 - Fotomicrografia da polpa de goiaba microencapsulada obtida por Mev, aumento de $1000 \mathrm{X}$. 
De modo geral a secagem por atomização levou a uma formação de partículas com formato esférico, com um leve grau aglomeração entre elas $\left(\mathrm{a}_{\mathrm{w}}=0,3047 \pm 0,0043\right)$. O tamanho das microcápsulas variou de 2,68 a 6,79 $\mu \mathrm{m}$ (Figura 2), sendo que a maioria das partículas apresentou tamanho na faixa de 4 a $6 \mu \mathrm{m}$.

Da mesma forma que ao verificado por Mata; Medeiros; Duarte (2005) quando realizaram a avalição do microencapsulamento do umbu em pó, neste estudo foi observado igualmente que as partículas pequenas tendem a aderir a partículas de maior grau de magnitude (Figura 3) e ainda não se evidenciou fragmentação de partículas ou rachadura de superfície, mas apenas amorfismo mínimo.

Osorio; Forero; Carriazo (2011), realizaram por Mev avaliação da goiaba microencapsulada com maltodextrina e goma arábica e obtiveram o mesmo formato das partículas, observando que a maioria do tamanho das partículas estava entre 3 e $5 \mu \mathrm{m}$. Os mesmos autores citam também, que a obtenção de partículas esféricas na microencapsulação demonstra um sucesso no processo.

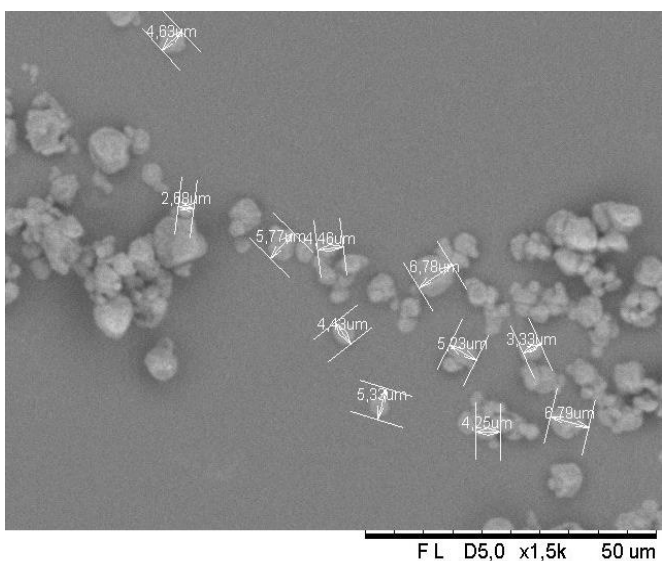

Figura 2 - Fotomicrografia da polpa de goiaba microencapsulada obtida por Mev, aumento de 1500 X.

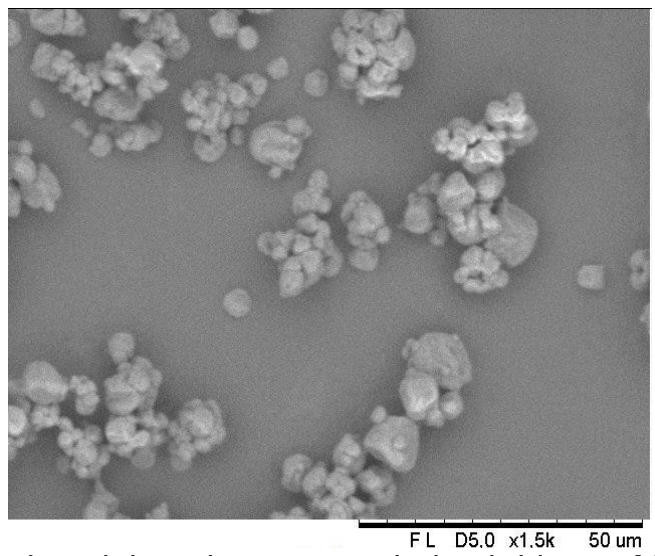

Figura 3 - Fotomicrografia da polpa de goiaba microencapsulada obtida por Mev, aumento de $2000 \mathrm{X}$. 


\section{CONCLUSÃO}

O processo utilizado para a microencapsulação da polpa de goiaba resultou na formação de partículas esféricas com um tamanho médio entre 4 a $6 \mu \mathrm{m}$, o que prevê um sucesso no processo de secagem por spray dryer.

\section{NOMENCLATURA}

$\begin{array}{ll}\mathrm{a}_{\mathrm{w}} & \text { Atividade de água } \\ \mathrm{g} & \text { Grama } \\ { }^{\circ} \mathrm{C} & \text { Grau Celsius } \\ \mathrm{Kg} & \text { Quilograma } \\ \mathrm{kV} & \text { Quilo volts } \\ \mathrm{L.h}-1 & \text { Litro por hora } \\ \mathrm{L.min}-1 & \text { Litro por minuto } \\ \mathrm{Mev} & \text { Microscopia eletrônica de varredura } \\ \mu \mathrm{m} & \text { Micrômetro } \\ \mathrm{mL} & \text { Mililitro } \\ \mathrm{mm} & \text { Milímetro } \\ \mathrm{MG} & \text { Microencapsulado de polpa de goiaba } \\ \mathrm{G} & \text { Polpa ou purê de goiaba } \\ \mathrm{rpm} & \text { Rotação por minuto }\end{array}$

\section{REFERÊNCIAS}


BRACKMANN, A.; ANESE, R. O.; BOTH, V.; THEWES, F. R.; FRONZA, D. Atmosfera controlada para o armazenamento de goiaba cultivar 'Paluma'. Rev. ceres, Viçosa, v. 59, n. 2, 2012.

BRASIL. Instrução Normativa n ${ }^{\circ}$ 01, de 07 de janeiro de 2000. Aprova o Regulamento Técnico Geral para fixação dos Padrões de Identidade e Qualidade para polpa de fruta. Ministério da agricultura e do abastecimento, Brasília, DF, 10 jan. 2000.

FREIRE, J. M.; ABREU, C. M. P.; CORRÊA, A. D.; SIMÃO, A. A.; SANTOS, C. M. dos. Avaliação de compostos funcionais e atividade antioxidante em farinhas de polpa de goiabas. Rev. bras. frutic., Jaboticabal, v. 34, n. 3, 2012.

HAIDA, K. S.; BARON, Â.; HAIDA, K. S.; FACI, D.; HASS, J.; SILVA, F. J. Compostos fenólicos totais e atividade antioxidante de duas variedades de goiaba e arruda. Rev. bras. ciênc. saúde, João Pessoa, n. 9, 2011.

MATA, M. E. R. M.;MEDEIROS, S.S.A.; DUARTE, M. E. E. Microencapsulamento do umbu em pó com diferentes formulações de maltodextrina: estudo do tamanho das partículas por microscopi eletrônica Rev. Bras. de Prod. Agroind., Campina Grande, v. 7, n.1, p.59-70, 2005.

NASCIMENTO, R. J. do. Potencial antioxidante de resíduo agroindustrial de goiaba. 2010. 110 f. Dissertação. (Mestrado em Ciência e Tecnologia de Alimentos) - Departamento de Ciências Domésticas da Universidade Federal Rural de Pernambuco, Recife, 2010.

OSORIO, C.; FORERO, D. P.; CARRIAZO, José G. Characterisation and performance assessment of guava (Psidium guajava L.) microencapsulates obtained by spray-drying. Food res. int., Essex, n. 44, 2011.

SANTOS, A. B.; FÁVARO-TRINDADE, C. S.; GROSSO, C. R. F. Preparo e caracterização de microcápsulas de oleoresina de páprica obtidas por atomização. Ciênc. tecnol. aliment., Campinas, v. 25, 2005. 